\title{
A numerical comparison of different methods for determining the particle formation rate
}

\author{
H. Vuollekoski ${ }^{1}$, S.-L. Sihto ${ }^{1}$, V.-M. Kerminen ${ }^{1,2}$, M. Kulmala ${ }^{1,3}$, and K. E. J. Lehtinen ${ }^{4,5}$ \\ ${ }^{1}$ Department of Physics, University of Helsinki, P.O. Box 48, 00014 Helsinki, Finland \\ ${ }^{2}$ Finnish Meteorological Institute, 00560 Helsinki, Finland \\ ${ }^{3}$ Department of Applied Environmental Science, Stockholm University, 10691 Stockholm, Sweden \\ ${ }^{4}$ Department of Physics and Mathematics, University of Eastern Finland, 70211 Kuopio, Finland \\ ${ }^{5}$ Finnish Meteorological Institute, 70211 Kuopio, Finland
}

Correspondence to: H. Vuollekoski (henri.vuollekoski@helsinki.fi)

Received: 18 June 2010 - Published in Atmos. Chem. Phys. Discuss.: 10 August 2010

Revised: 21 February 2012 - Accepted: 21 February 2012 - Published: 1 March 2012

\begin{abstract}
Different methods of determining formation rates of $3 \mathrm{~nm}$ particles are compared, basing on analysis of simulated data, but the results are valid for analyses of experimental particle size distribution data as well, at least within the accuracy of the applied model. The study shows that the method of determining formation rates indirectly from measured number concentration data of 3-6 nm particles is generally in good agreement with the theoretical calculation with a systematic error of 0-20\%. While this accuracy is often enough, a simple modification to the approximative equation for the formation rate is recommended. A brief study on real atmospheric data implied that in some cases the accuracy gain may be significant.
\end{abstract}

\section{Introduction}

Formation of new particles by nucleation and their subsequent growth to larger sizes have been observed to take place frequently and almost everywhere in the Earth's atmosphere (Kulmala et al., 2004; Kulmala and Kerminen, 2008). Model studies indicate that nucleation is a dominant source of new particles (Spracklen et al., 2006; Yu and Luo, 2009) and a very important source of cloud condensation nuclei and cloud droplets (Spracklen et al., 2008; Makkonen et al., 2009; Merikanto et al., 2009; Pierce and Adams, 2009) in the global atmosphere.

From a theoretical point of view, atmospheric new-particle formation is driven by the nucleation rate, i.e. the formation rate of critical clusters of $1-2 \mathrm{~nm}$ in diameter (e.g. Kulmala et al., 2007). The nucleation rate is, however, a problematic quantity to deal with. Firstly, in spite of the recent progress in measuring atmospheric clusters and nanometer-size particles (Sipilä et al., 2008; Iida et al., 2009; Lehtipalo et al., 2009; Manninen et al., 2009), accurate measurements of atmospheric nucleation rates are impossible at the moment. Secondly, few large-scale atmospheric models extend their size distribution down to $1 \mathrm{~nm}$ needed to simulate the nucleation process. Atmospheric new-particle formation is therefore usually handled by using the concept of the "apparent" particle formation rate (e.g. Kerminen and Kulmala, 2002), which refers to the formation rate of particles of a few nm (typically $3 \mathrm{~nm}$ ) in diameter.

The connection between the nucleation rate and apparent particle formation rate has been studied quite actively during the recent years (e.g. Kerminen et al., 2004; McMurry et al., 2005; Lehtinen et al., 2007; Anttila et al., 2010). Much less attention has been put on investigating how accurately the particle formation rate can be determined from atmospheric measurements, how sensitive this rate is to the applied analysis method and the underlying assumptions, and how this rate should be related to the nucleation rate in practice. Such information would be extremely valuable when testing current nucleation theories against field or laboratory measurement data, or when evaluating the performance of nucleation parameterizations in large-scale atmospheric models.

The goal of this paper is to address some of the issues raised above with help of an aerosol dynamics model. By using simulated, rather than measured, data, it is possible to investigate the particle formation rate and related quantities 
in a controlled system and without the problems inherent to experimental data. The latter include the diurnal evolution of the atmospheric boundary layer, rapid changes in air masses transported to the measurement site, and uncertainties in the determination of particle growth rate. In this study we used the University of Helsinki Multicomponent Aerosol model, which is known to be capable of describing the general characteristics of new particle formation in an idealized scenario (Korhonen et al., 2004). Since the model is built on the same physical assumptions as the methods investigated in this paper, and since we treat our simulation data as if it were traditional field measurement data, our results should be valid for analyses of experimental data as well.

\section{Theory}

The time evolution of particle size distribution is described by the (simplified) continuous general dynamic equation (e.g. Seinfeld and Pandis, 2006)

$$
\begin{aligned}
& \frac{\partial n(v, t)}{\partial t}=\frac{1}{2} \int_{0}^{v} K(v-q, q) n(v-q, t) n(q, t) d q-n(v, t) \int_{0}^{\infty} K(q, v) n(q, t) d q \\
& -\frac{\partial}{\partial v}\left[\left(p_{k}-\gamma_{k}\right) v_{1} n(v, t)\right]+J_{\text {nuc }}(t) \delta\left(v-v_{0}\right)+S(v, t)-R(v, t),
\end{aligned}
$$

where $n(v, t)=\partial N / \partial v$ is the particle volume distribution function, $v$ is particle volume, $t$ is time, $N$ is the cumulative number concentration of particles, $K\left(v, v^{\prime}\right)$ is the coagulation coefficient between particles of volumes $v$ and $v^{\prime}, p_{k}$ and $\gamma_{k}$ are the rates at which a $k$-mer gain or lose a monomer due to condensation or evaporation, $v_{1}$ is the volume of the condensing/evaporating monomer, $J_{\text {nuc }}$ is the nucleation rate, $\delta$ is the delta function, $v_{0}$ is the volume of nucleated particles, and $S$ and $R$ represent additional sources and losses. Note that the quantities are defined here in the continuous volume sense, while in this paper we investigate both continuous and discrete quantities.

In this paper, the particles are assumed to be spherical, and so it is more practical to use particle diameter instead of volume. While it can be defined at any size, let us, for the remainder of this paper, assume that by formation rate we mean it at the most widely studied diameter $D_{p}=3 \mathrm{~nm}$, unless stated otherwise. Even though recent measurements have been able to estimate particle formation rates at as low as $2 \mathrm{~nm}$ (Kulmala et al., 2007; Manninen et al., 2009), only a fraction of available measurement data extend to below $3 \mathrm{~nm}$. Since the mathematical relations used in this paper are applicable at any size, a more conventional size of $3 \mathrm{~nm}$ is also more meaningful from the point of view of this study, as the diameter change from nucleation to $3 \mathrm{~nm}$ is much larger than to $2 \mathrm{~nm}$, allowing for more time for e.g. coagulation.

Particles of $3 \mathrm{~nm}$ in diameter may be formed due to condensational growth of particles from below $3 \mathrm{~nm}$, shrinkage of particles due to evaporation from above $3 \mathrm{~nm}$, and selfcoagulation of particles smaller than $3 \mathrm{~nm}$. Since nuclei self- coagulation is important at high nucleation rates only, it may be neglected in typical atmospheric conditions (e.g. Anttila et al., 2010). While keeping these assumptions in mind, we denote the formation rate of particles at $3 \mathrm{~nm}$ by $J_{3}$. In words, this signifies the flux of particle concentration on "diameter axis" at exactly $3 \mathrm{~nm}$ in size. An equation for this can then be written as

$J_{3}=n_{3} \times G R_{3}=\left.\frac{\partial N}{\partial D_{p}}\right|_{3} G R_{3}$,

where $n_{3}=\partial N /\left.\partial D_{p}\right|_{3}$ is from now on the size distribution function at $3 \mathrm{~nm}, \mathrm{GR}_{3}=d D_{p} /\left.d t\right|_{3}$ is the growth rate of particles at $3 \mathrm{~nm}$, which represents the term $\left(p_{k}-\gamma_{k}\right) v_{1}$ in Eq. (1): the growth due to condensation and shrinkage due to evaporation.

Note that in a stationary situation $\partial N /\left.\partial t\right|_{3}=0$, but according to Eq. (2) the formation rate $J_{3}$ need not equal zero.

\section{Methods}

Unfortunately, the presented definition of the formation rate, Eq. (2), is difficult to apply in practise. In a sectional aerosol dynamics model, the formation rate can be estimated by approximating the partial derivative, and interpolating (if needed) over particle diameter, to get

$J_{3}=\left.\frac{\Delta N}{\Delta D_{p}}\right|_{3} \times \mathrm{GR}_{3}$,

where $\Delta D_{p}$ is the width of the section centered around $3 \mathrm{~nm}$ particles, and $\Delta N$ is the particle concentration in the corresponding section. Note that since the efficacy of coagulation decreases with increasing particle size, particles between the lower limit and the middle of a size section are scavenged more effectively than particles closer to the upper limit of the same size section. This means that the $J_{3}$ calculated with Eq. (3) actually corresponds to the formation rate at a size slightly larger than the center of the bin. With typical atmospheric particle concentrations, however, this effect becomes important only if the size resolution of the data is very coarse, and, in practise, below $2 \mathrm{~nm}$.

In this study we used the University of Helsinki Multicomponent Aerosol model (UHMA, Korhonen et al. (2004)) to produce the data for analysis. UHMA is a size segregated sectional box model that includes all basic aerosol dynamical processes. A model has the advantage over atmospheric measurements that anything modeled can also be output and saved for further analysis, thereby allowing us to test various different methods of data analysis. In this study we used a $1 \mathrm{~min}$ output time resolution with 60 fixed size sections divided logarithmically between particle diameters $1.5-1000 \mathrm{~nm}$. New particles were assumed to be formed via the sulphuric acid induced cluster activation (Kulmala 
et al., 2006) at the smallest model section. Note that due to the methods used in the data analysis of this study, and the accompanying sensitivity checks, the selected nucleation mechanism is of minor importance.

State-of-the-art instruments, on the other hand, lack detailed resolution in both time and size. In general, noise and other experimental errors decrease their accuracy. In case of an instrument that divides particles according to size channels, such as the differential mobility particle sizer (DMPS, e.g. Aalto et al. (2001)), one could in principle directly apply Eq. (3). However, since the DMPS has a lower size limit at $3 \mathrm{~nm}$, it is practically impossible to determine $\mathrm{GR}_{3}$ accurately from DMPS size distribution data. Instead, it is easier to estimate an average growth rate from the rate of change in mode diameter of particles from a wider size range, e.g. (roughly) 3-7 nm (Sihto et al., 2006; Riipinen et al., 2007). Also, using data originating only from one instrument channel is unreliable. Therefore, it is practical to determine the formation rate via the number concentration of e.g. 3-6 nm particles, $N_{3-6}$. By integrating Eq. (1) over 3-6 nm, and neglecting the self-coagulation as well as other small terms, we get a balance equation

$\frac{\partial N_{3-6}}{\partial t}=\mathrm{GR}_{3} \times n_{3}-\mathrm{GR}_{6} \times n_{6}-\mathrm{CoagS}_{3-6} \times N_{3-6}$,

where the terms on the right-hand-side represent growth from below $3 \mathrm{~nm}$, growth past $6 \mathrm{~nm}$ and coagulation loss within 3$6 \mathrm{~nm}$, respectively. $\mathrm{CoagS}_{3-6}$ is the mean coagulation sink experienced by $3-6 \mathrm{~nm}$ particles (Kulmala et al., 2001). To facilitate its calculation, this range of coagulation sinks may be approximated by just CoagS 4 , as $4 \mathrm{~nm}$ is close to the geometric mean of 3-6 nm. By rearranging the terms of Eq. (4), approximating the differentials by finite differences, approximating $\mathrm{GR}_{6}$ by the average growth rate of $3-7 \mathrm{~nm}$ particles $\mathrm{GR}_{3-7}$, and denoting the first term on the right-hand-side of Eq. (4) by $J_{3}$, we get (e.g. Sihto et al., 2006; Riipinen et al., 2007)

$J_{3}=\frac{\Delta N_{3-6}}{\Delta t}+\mathrm{CoagS}_{4} \times N_{3-6}+\frac{\mathrm{GR}_{3-7}}{6 n m-3 n m} \times N_{3-6}$.

We will use this equation as the measurement perspective, while all the analyses in this paper are still performed on simulated data.

Several approximations were made to arrive at Eq. (5), but it is unclear what is the magnitude of error in this approach. In experimental observations, number concentrations are usually directly measured, while the coagulation sink and growth rate are calculated from the number concentration data. Since the growth rate may be a several-hour average, it is a potential source of error. On the other hand, the size resolution of the measurement device might be inadequate to give an accurate estimate of the particle concentration at the exact size range of 3-6 $\mathrm{nm}$. We will calculate $N_{3-6}$ in two ways: (1) by approximating it as a sum of particle concentrations within bins in size region $3-6 \mathrm{~nm}$, and

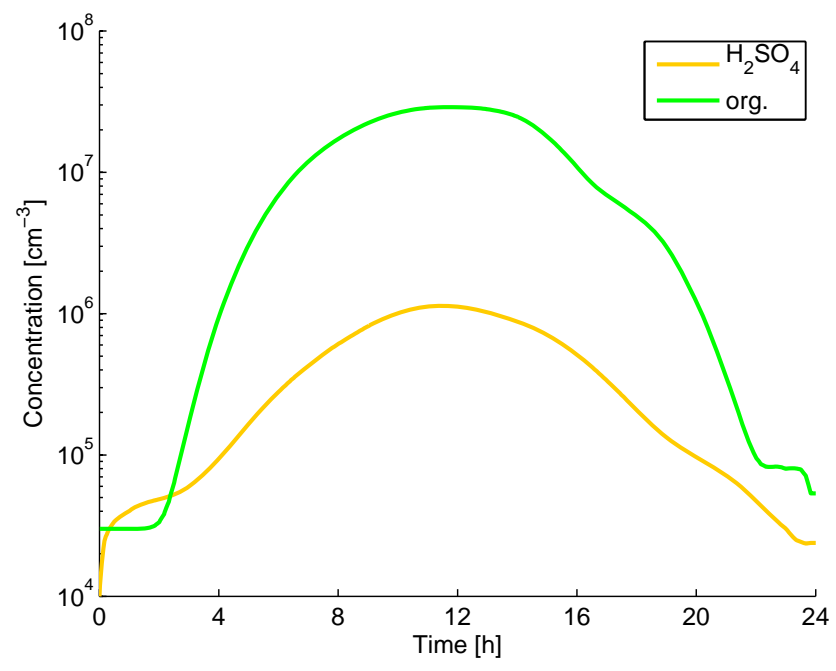

Fig. 1. The concentrations of sulphuric acid and a non-volatile organic vapour used in the simulations. Note that as the concentration of the organic vapor is significantly higher than that of sulphuric acid, the organic vapor will cause most of the growth in particles.

(2) by using more accurate numerical integration. We will also try several other particle size ranges in the application of Eq. (5).

\section{Results and discussion}

\subsection{Comparison of different methods for estimating the formation rate}

We calculated the formation rate of $3 \mathrm{~nm}$ particles by using Eqs. (3) and (5) (the "theoretical" and "measured" formation rates, respectively) from simulated new particle formation event data. Note that the simulations and methods of data analysis were independent of each other. The vapour concentrations used in the simulation are presented in Fig. 1: the particles grow due to condensation of sulphuric acid and a non-volatile organic vapour with a significantly higher concentration. These cause growth of particles of all sizes, and most of this growth can be attributed to the organic vapour. The only organic vapour considered was set non-volatile, because otherwise the Kelvin effect would significantly hinder its condensation on particles around the $3 \mathrm{~nm}$ size. A surface plot of the simulated particle size distribution data is presented in Fig. 2.

A comparison of formation rates is presented in Fig. 3, in which the "measured" formation rate was determined in two ways: by using a time dependent but size-averaged growth rate for 3-7 nm particles (solid black line), and by using a single value for the growth rate estimated visually from the particle size distribution plot $\left(3 \mathrm{~nm} \mathrm{~h}^{-1}\right.$, dashed red line). With this parameterization, the "measured" formation rate overestimates the theoretical one (blue line with circles) by 


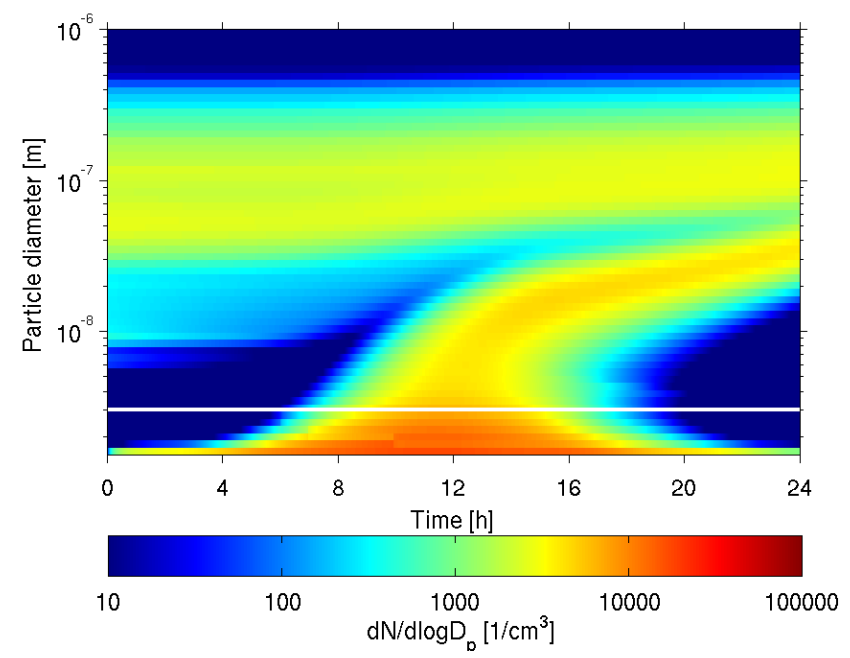

Fig. 2. The simulated particle size distribution data used in the analysis.

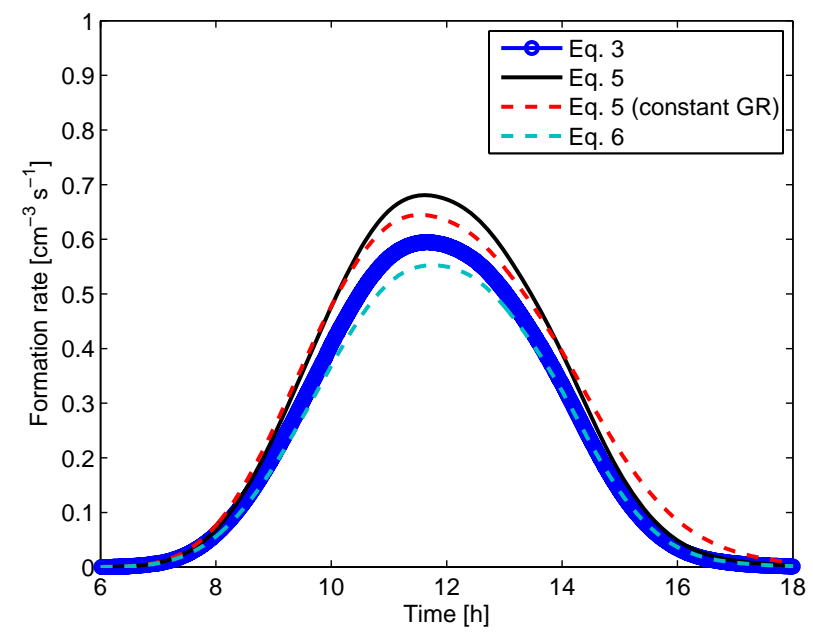

Fig. 3. Comparison of formation rates calculated using different methods during a simulated new particle formation event.

$10-15 \%$. Nevertheless, the two equations are in a surprisingly good agreement, especially when the growth rate was visually estimated. The dashed light green line represents the improved Eq. (6) with the same growth rate as in the solid black line (see below).

The terms from the Eq. (5) are plotted for comparison in Fig. 4. One might suggest that a poorly estimated growth rate could make the "measured" formation rate deviate significantly from the "theoretical" one. The magnitude and order of importance of different terms depend on the conditions of the new particle formation event. For example, a higher concentration of pre-existing (background) particles would amplify the coagulation sink. Consequently, the number concentration of 3-6 nm particles would decrease, affecting all terms in Eq. (5). However, due to the more direct effect of

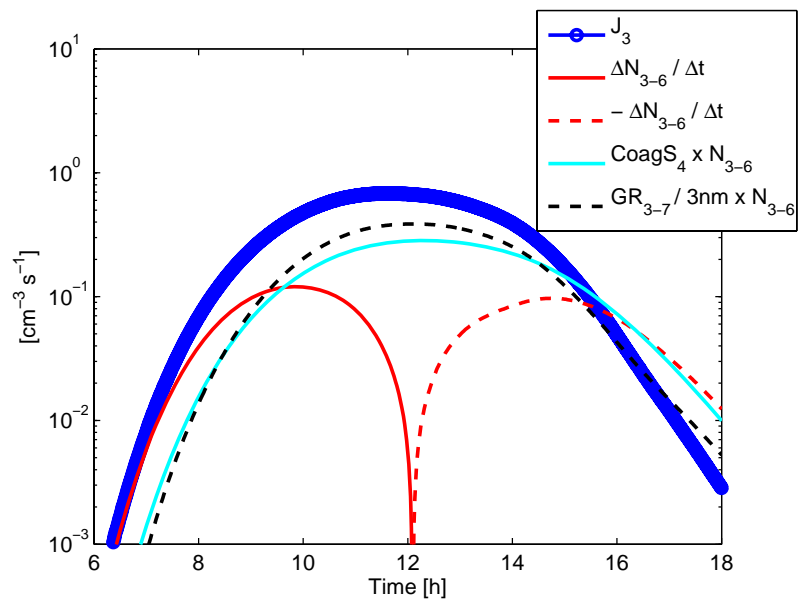

Fig. 4. Comparison of different terms contributing to the Eq. (5) for formation rate. The positive and negative parts of the $\Delta N_{3-6} / \Delta t$ term are plotted separately.

the pre-existing particles on the coagulation sink, the coagulation term would increase the most. Therefore, the error from using Eq. (5) instead of Eq. (3) might increase.

We investigated how the ratio between $J_{3}$ calculated by using Eqs. (3) and (5) would change, when varying the cluster activation coefficient (Kulmala et al., 2006) used in nucleation, the concentration of condensing (particle-growing) vapour and the number concentration of background particles. The results are presented in Table 1, with each entry representing an independent simulation, together capturing the general trends in all basic scenarios. The investigation showed that changing the activation coefficient has very little effect on the ratio between the two values os $J_{3}$. On the other hand, if the concentration of the organic vapour was increased, the growth rate would be higher and more particles would grow to $3-6 \mathrm{~nm}$ before being coagulated. Because the loss due to coagulation is most significant for particles below $3 \mathrm{~nm}$, this would decrease the importance of the coagulation term, which would then again bring the ratio between the formation rates closer to unity. Similarly, if the pre-existing particle concentration was decreased, the coagulation term would weaken, and Eqs. (3) and (5) would give more similar values for $J_{3}$.

In deriving Eq. 5) from Eq. (4), several approximations were made. We performed more detailed calculations on the first simulation in Table 1, and the results are presented in Table 2. For example, the actual coagulation sink of $3-$ $6 \mathrm{~nm}$ particles was approximated by that of $4 \mathrm{~nm}$ particles. By comparing these coagulation sinks, we found that this approximation causes an error of about $8 \%$ in the value of $\mathrm{CoagS}_{3-6}$. By applying this improved coagulation sink in Eq. (5), the ratio of formation rates was closer to unity. We also studied the second approximation of Eq. (5), i.e. the decision to use the averaged growth rate of $3-7 \mathrm{~nm}$ particles, 
Table 1. Sensitivity of the ratio of formation rates (Eq. (3)/Eq. (5), calculated as a mean of values during 11:00-13:00) to different parameters affecting new particle formation. Nomenclature: $\mathrm{BKG}=$ background particle concentration, $A=$ activation coefficient, bins $=$ number of size sections.

\begin{tabular}{|c|c|}
\hline Varied parameter & Ratio \\
\hline none & 0.87 \\
\hline $\mathrm{BKG} \rightarrow 0$ & 1.00 \\
\hline $\mathrm{BKG} \rightarrow \frac{1}{10} \times \mathrm{BKG}$ & 0.96 \\
\hline $\mathrm{BKG} \rightarrow \frac{1}{2} \times \mathrm{BKG}$ & 0.91 \\
\hline $\mathrm{BKG} \rightarrow 4 \times \mathrm{BKG}$ & 0.84 \\
\hline$A \rightarrow \frac{1}{4} \times \mathrm{A}$ & 0.87 \\
\hline$A \rightarrow 4 \times \mathrm{A}$ & 0.87 \\
\hline $\mathrm{GR}_{3-7} \rightarrow 0.77 \times \mathrm{GR}_{3-7}$ & 0.78 \\
\hline $\mathrm{GR}_{3-7} \rightarrow 1.9 \times \mathrm{GR}_{3-7}$ & 0.97 \\
\hline bins $\rightarrow \frac{2}{3} \times$ bins & 0.89 \\
\hline bins $\rightarrow 2.5 \times$ bins & 0.85 \\
\hline
\end{tabular}

and found that using a more accurate growth rate of exactly $6 \mathrm{~nm}$ particles has an insignificant effect on the value of the formation rate. The remaining approximated quantity in Eq. (5), i.e. the number concentration of 3-6 $\mathrm{nm}$ particles, may also be defined more accurately. As opposed to calculating $N_{3-6}$ simply as a sum of particle concentrations in bins within 3-6 nm, a more accurate numerical integration increases the term, and the ratio between the formation rates actually decreases by $7 \%$. In total, using all of the mentioned "improvements" decreases the ratio between the formation rates by $4 \%$ in the studied case.

We also tested how the ratio between the formation rates (Eqs. (3) and (5)) would change if the particle diameter range in Eq. (5) would be different from 3-6 nm. The results of this analysis are presented in Table 2. Here, all the "improvements" suggested in the previous paragraph were applied, and all occurrences of $6 \mathrm{~nm}$ in the modified Eq. (5) were replaced with the new upper limit of the diameter range. Perhaps a bit surprisingly, our sensitivity test suggests that the applied particle diameter range affects the accuracy of $J_{3}$ significantly, with a broader range giving greater accuracy, until 3-13 nm, after which the applied Eq. (5) begins to underestimate the formation rate. Of course, this is caused by a numerical effect: the significant increase in the denominator of the growth rate term in Eq. (5) decreases its value. While increasing the level of agreement between the two equations for formation rates, the difference caused by the coagulation term remains. Obviously the exact numbers presented in Table 2 will vary depending on the case: for example, for the case which we used to study the effect of halving the background particle concentration, the maximum ratio occurs with the diameter range of $3-18 \mathrm{~nm}$.

Another factor that could have an effect on the formation rates is the size resolution of the data, or in this case, the
Table 2. Sensitivity of the ratio of formation rates (Eq. (3)/Eq. (5), calculated as a mean of values during 11:00-13:00) to modifications and improvements in analysis. The first three improvements are included in all the latter ones (applied at the respective size range).

\begin{tabular}{ll}
\hline Modification of Analysis & Ratio \\
\hline none & 0.87 \\
$\mathrm{CoagS}_{4} \rightarrow \mathrm{CoagS}_{3-6}$ & 0.91 \\
$\mathrm{GR}_{3-7} \rightarrow \mathrm{GR}_{6}$ & 0.86 \\
more accurate $N_{3-6}$ & 0.80 \\
\hline all of the above & 0.83 \\
using 3-4 nm range & 0.80 \\
using 3-7 nm range & 0.84 \\
using 3-10 nm range & 0.92 \\
using 3-13 nm range & 1.00 \\
using 3-15 nm range & 1.06 \\
using 3-25 nm range & 1.41 \\
$N_{3-6} / 3 \mathrm{~nm} \rightarrow N_{5-7} / 2 \mathrm{~nm}$ & 1.06 \\
\hline
\end{tabular}

number of sections in the model. A brief sensitivity test suggested that a higher size resolution would magnify the difference between the formation rates predicted by Eqs. (3) and (5), but only slightly (cf. Table 1).

In order to compare the particle formation rates at $2 \mathrm{~nm}$, we performed a brief test on the ratio between Eq. (3) applied at $2 \mathrm{~nm}$ and Eq. (5) applied with the diameter range $2-3 \mathrm{~nm}$ (Kulmala et al., 2007). The ratio between these two values for $J_{2}$ was 0.73 using the "improved" analysis (see above) with the reference data. Scavenging of $2 \mathrm{~nm}$ particles is twice as fast as that of $3 \mathrm{~nm}$ particles, which is the reason for the increased disagreement between the two formation rates as compared to the $J_{3}$ analysis above. As was in the case of $J_{3}$, the ratio increased as upper limit of the diameter range was broadened, reaching unity around $7 \mathrm{~nm}$ in the analysed data.

The presented results suggest that most of the deviation between Eqs. (3) and (5) is caused by coagulation. However, the error rises not only from the coagulation term of Eq. (5), but from approximating the last term, $n_{6}$, by $N_{3-6} / 3 \mathrm{~nm}$, a particle diameter range that is significantly affected by coagulation scavenging. Since the coagulation sink decreases with increasing particle size, a better solution would be estimating $n_{6}$ from a size range closer to $6 \mathrm{~nm}$, for example

$J_{3}=\frac{\Delta N_{3-6}}{\Delta t}+\mathrm{CoagS}_{4} \times N_{3-6}+\frac{\mathrm{GR}_{3-7}}{7 n m-5 n m} \times N_{5-7}$.

The ratio between Eqs. (3) and (6) was found to be 1.06, which could be said to be a significant improvement over the results shown above. Also, if the last term $\mathrm{GR}_{3-7} / 2 \mathrm{~nm}$ $\times N_{5-7}$ was replaced by $J_{6}$ (as calculated from Eq. (3) at $6 \mathrm{~nm}$ ), the error of $J_{3}$ was found to be within $1 \%$ as compared to Eq. (3). Because Eq. (6) is easily implemented in data analysis, we recommend its usage over Eq. (5).

Obviously the numbers presented in Tables 1 and 2 are examples for the studied case, and cannot be used to accurately 


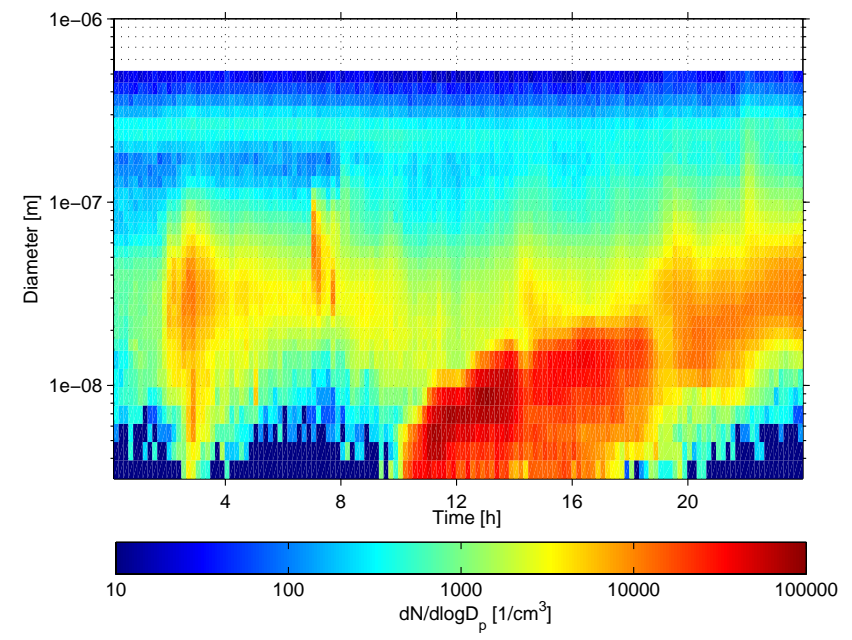

Fig. 5. The particle size distribution data measured by a DMPS in Hyytiälä, Finland, on 1 April 2003.

quantify a systematic error. Nevertheless the trends related to and approximate magnitudes of different aerosol dynamical phenomena should be general.

\subsection{Example of atmospheric application}

In order to demonstrate the practical usage of Eq. (6), we applied it on real atmospheric data from a DMPS instrument in Hyytiälä, Finland, on 1 April 2003. The particle size distribution is shown in Fig. 5. We used the constant value of $3.4 \mathrm{~nm} \mathrm{~h}^{-1}$ for the particle growth rate during the nucleation period from 10:00 to 18:00. For details on how the growth rate was estimated, please see Hirsikko et al. (2005).

The median value for the formation rate of $3 \mathrm{~nm}$ particles calculated by using Eq. (5) was $1.75 \mathrm{~cm}^{-3} \mathrm{~s}^{-1}$, whereas Eq. (6) gave $1.13 \mathrm{~cm}^{-3} \mathrm{~s}^{-1}$. This means that in this particular case, the difference between the two methods of calculating $J_{3}$ was as large as $54 \%$.

\section{Summary and conclusions}

Different methods of determining formation rates of $3 \mathrm{~nm}$ particles were compared. The comparison was based on data analysis performed on output data from a sectional aerosol dynamics model in various cases of differing model parameters. However, the results are valid for experimental discrete particle size distribution analyses as well. The study showed that the method of determining formation rates indirectly from the measured concentration of 3-6 nm particles (Eq. (5), e.g. Sihto et al. (2006)) is generally in good agreement with the more accurate Eq. (3) with a systematic error of $0-20 \%$ that can mostly be attributed to coagulation. The error is reduced by a few percents if the coagulation sink is calculated more accurately, or if the growth rate is very high, or if the background particle concentration is relatively insignificant. However, testing the improved equation on real atmospheric data showed that in some cases the difference between the formation rates calculated from Eqs. (5) and (6) may be significantly higher.

It can be concluded that the general uncertainties related to experimental measurements often exceed the error caused by using approximative expressions for formation rate, and both studied methods are accurate enough in atmospheric applications. Nevertheless, since the presented modification (Eq. (6)) is easily applied in data analysis, we recommend its usage in determination of particle formation rate from atmospheric data.

Acknowledgements. The financial support by the Academy of Finland Centre of Excellence program (project no. 1118615) is gratefully acknowledged. This work has been partially funded by European Commission 6th Framework programme project EUCAARI, contract no. 036833-2 (EUCAARI).

Edited by: E. Swietlicki

\section{References}

Aalto, P., Hämeri, K., Becker, E., Weber, R., Salm, J., Mäkelä, J. M., Hoell, C., O’Dowd, C. D., Karlsson, H., Hansson, H., Väkevä, M., Koponen, I., Buzorius, G., and Kulmala, M.: Physical characterization of aerosol particles during nucleation events, Tellus B - Chem. Phys. Meteorol., 53, 344-358, 2001.

Anttila, T., Kerminen, V.-M., and Lehtinen, K. E. J.: Parameterizing the formation rate of new particles: The effect of nuclei selfcoagulation, J. Aerosol Sci., 41, 621-636, 2010.

Hirsikko, A., Laakso, L., Hõrrak, U., Aalto, P. P., Kerminen, V.M., and Kulmala, M.: Annual and size dependent variation of growth rates and ion concentrations in boreal forest, Boreal Environ. Res., 10, 357-369, 2005.

Iida, K., Stolzenburg, M. R., and McMurry, P. H.: Effect of Working Fluid on Sub-2 nm Particle Detection with a Laminar Flow Ultrafine Condensation Particle Counter, Aerosol Sci. Technol., 43, 81-96, doi:10.1080/02786820802488194, 2009.

Kerminen, V.-M. and Kulmala, M.: Analytical formulae connecting the "real" and the "apparent" nucleation rate and the nuclei number concentration for atmospheric nucleation events, J. Aerosol Sci., 33, 609-622, 2002.

Kerminen, V.-M., Anttila, T., Lehtinen, K. E. J., and Kulmala, M.: Parameterization for atmospheric new-particle formation: Application to a system involving sulfuric acid and condensable watersoluble organic vapors, Aerosol Sci. Technol., 38, 1001-1008, doi:10.1080/027868290519085, 2004.

Korhonen, H., Lehtinen, K. E. J., and Kulmala, M.: Multicomponent aerosol dynamics model UHMA: model development and validation, Atmos. Chem. Phys., 4, 757-771, doi:10.5194/acp-4757-2004, 2004.

Kulmala, M. and Kerminen, V.-M.: On the formation and growth of atmospheric nanoparticles, Atmos. Res., 90, 132-150, doi:10.1016/j.atmosres.2008.01.005, 2008.

Kulmala, M., Dal Maso, M., Mäkelä, J., Pirjola, L., Väkevä, M., Aalto, P., Miikkulainen, P., Hameri, K., and O'Dowd, C. D.: On 
the formation, growth and composition of nucleation mode particles, Tellus B - Chem. Phys. Meteorol., 53, 479-490, 2001.

Kulmala, M., Vehkamäki, H., Petäjä, T., Dal Maso, M., Lauri, A., Kerminen, V.-M., Birmili, W., and McMurry, P.: Formation and growth rates of ultrafine atmospheric particles: a review of observations, J. Aerosol Sci., 35, 143-176, doi:10.1016/j.jaerosci.2003.10.003, 2004.

Kulmala, M., Lehtinen, K. E. J., and Laaksonen, A.: Cluster activation theory as an explanation of the linear dependence between formation rate of $3 \mathrm{~nm}$ particles and sulphuric acid concentration, Atmos. Chem. Phys., 6, 787-793, 2006, http://www.atmos-chem-phys.net/6/787/2006/.

Kulmala, M., Riipinen, I., Sipilä, M., Manninen, H. E., Petäjä, T., Junninen, H., Dal Maso, M., Mordas, G., Mirme, A., Vana, M., Hirsikko, A., Laakso, L., Harrison, R., Hanson, I., Leung, C., Lehtinen, K. E. J., and Kerminen, V.-M.: Toward direct measurement of atmospheric nucleation, Science, 318, 89-92, doi:10.1126/science.1144124, 2007.

Lehtinen, K. E. J., Dal Maso, M., Kulmala, M., and Kerminen, V.-M.: Estimating nucleation rates from apparent particle formation rates and vice versa: Revised formulation of the Kerminen-Kulmala equation, J. Aerosol Sci., 38, 988-994, doi:10.1016/j.jaerosci.2007.06.009, 2007.

Lehtipalo, K., Sipilä, M., Riipinen, I., Nieminen, T., and Kulmala, M.: Analysis of atmospheric neutral and charged molecular clusters in boreal forest using pulse-height CPC, Atmos. Chem. Phys., 9, 4177-4184, doi:10.5194/acp-9-4177-2009, 2009.

Makkonen, R., Asmi, A., Korhonen, H., Kokkola, H., Jarvenoja, S., Raisanen, P., Lehtinen, K. E. J., Laaksonen, A., Kerminen, V.M., Järvinen, H., Lohmann, U., Bennartz, R., Feichter, J., and Kulmala, M.: Sensitivity of aerosol concentrations and cloud properties to nucleation and secondary organic distribution in ECHAM5-HAM global circulation model, Atmos. Chem. Phys., 9, 1747-1766, doi:10.5194/acp-9-1747-2009, 2009.

Manninen, H. E., Petäjä, T., Asmi, E., Riipinen, I., Nieminen, T., Mikkilä, J., Hõrrak, U., Mirme, A., Mirme, S., Laakso, L., Kerminen, V.-M., and Kulmala, M.: Long-term field measurements of charged and neutral clusters using Neutral cluster and Air Ion Spectrometer (NAIS), Boreal Environ. Res., 14, 591-605, 2009.

McMurry, P. H., Fink, M., Sakurai, H., Stolzenburg, M. R., Mauldin, R. L., Smith, J., Eisele, F., Moore, K., Sjostedt, S., Tanner, D., Huey, L. G., Nowak, J. B., Edgerton, E., and Voisin, D.: A criterion for new particle formation in the sulfur-rich Atlanta atmosphere, J. Geophys. Res.-Atmos., 110, D22S02, doi:10.1029/2005JD005901, 2005.
Merikanto, J., Spracklen, D. V., Mann, G. W., Pickering, S. J., and Carslaw, K. S.: Impact of nucleation on global CCN, Atmos. Chem. Phys., 9, 8601-8616, doi:10.5194/acp-9-8601-2009, 2009.

Pierce, J. R. and Adams, P. J.: Uncertainty in global CCN concentrations from uncertain aerosol nucleation and primary emission rates, Atmos. Chem. Phys., 9, 1339-1356, doi:10.5194/acp-91339-2009, 2009.

Riipinen, I., Sihto, S.-L., Kulmala, M., Arnold, F., Dal Maso, M., Birmili, W., Saarnio, K., Teinilä, K., Kerminen, V.-M., Laaksonen, A., and Lehtinen, K. E. J.: Connections between atmospheric sulphuric acid and new particle formation during QUEST III-IV campaigns in Heidelberg and Hyytiälä, Atmos. Chem. Phys., 7, 1899-1914, doi:10.5194/acp-7-1899-2007, 2007.

Seinfeld, J. H. and Pandis, S. N.: Atmospheric Chemistry and Physics - From Air Pollution to Climate Change (2nd Edition), Wiley, 1225 pp., ISBN:978-0-471-72018-8, 2006.

Sihto, S.-L., Kulmala, M., Kerminen, V.-M., Dal Maso, M., Petäjä, T., Riipinen, I., Korhonen, H., Arnold, F., Janson, R., Boy, M., Laaksonen, A., and Lehtinen, K. E. J.: Atmospheric sulphuric acid and aerosol formation: implications from atmospheric measurements for nucleation and early growth mechanisms, Atmos. Chem. Phys., 6, 4079-4091, doi:10.5194/acp-6-4079-2006, 2006.

Sipilä, M., Lehtipalo, K., Kulmala, M., Petäjä, T., Junninen, H., Aalto, P. P., Manninen, H. E., Kyrö, E.-M., Asmi, E., Riipinen, I., Curtius, J., Kurten, A., Borrmann, S., and O'Dowd, C. D.: Applicability of condensation particle counters to measure atmospheric clusters, Atmos. Chem. Phys., 8, 4049-4060, doi:10.5194/acp-8-4049-2008, 2008.

Spracklen, D., Carslaw, K., Kulmala, M., Kerminen, V.-M., Mann, G., and Sihto, S.-L.: The contribution of boundary layer nucleation events to total particle concentrations on regional and global scales, Atmos. Chem. Phys., 6, 5631-5648, doi:10.5194/acp-6-5631-2006, 2006.

Spracklen, D., Carslaw, K., Kulmala, M., Kerminen, V.-M., Sihto, S.-L., Riipinen, I., Merikanto, J., Mann, G., Chipperfield, M., Wiedensohler, A., Birmili, W., and Lihavainen, H.: Contribution of particle formation to global cloud condensation nuclei concentrations, Geophys. Res. Lett., 35, L06808, doi:10.1029/2007GL033038, 2008.

Yu, F. and Luo, G.: Simulation of particle size distribution with a global aerosol model: contribution of nucleation to aerosol and CCN number concentrations, Atmos. Chem. Phys., 9, 76917710, doi:10.5194/acp-9-7691-2009, 2009. 